\title{
The Emerging Role of Cables1 in Cancer and Other Diseases
}

\author{
Jia-Rong Huang, Guang-Mou Tan, Yong Li, and Zhi Shi
}

Department of Cell Biology \& Institute of Biomedicine, National Engineering Research Center of Genetic Medicine, Guangdong Provincial Key Laboratory of Bioengineering Medicine, College of Life Science and Technology, Jinan University, Guangzhou, Guangdong, People's Republic of China (J.-R.H., Z.S.); Department of Head \& Neck Surgery, Affiliated Cancer Hospital \& Institute of Guangzhou Medical University, Guangzhou, Guangdong, People's Republic of China (G.-M.T.); and Department of Gastrointestinal Surgery \& General Surgery, Guangdong General Hospital, Guangdong Academy of Medical Sciences, Guangzhou, Guangdong, People's Republic of China (Y.L.)

Received December 2, 2016; accepted January 18, 2017

\section{ABSTRACT}

Cdk5 and Abl enzyme substrate 1 (Cables 1$)$ is an adaptor protein that links cyclin-dependent kinase (Cdks) with nonreceptor tyrosine kinases and regulates the activity of Cdks by enhancing their Y15 phosphorylation. Emerging evidence also shows that Cables 1 can interact with, for example, p53 family proteins, 14-3-3, and $\beta$-catenin, suggesting that Cables 1 may be a signaling hub for the regulation of cell growth. Abnormal expression of Cables 1 has been observed in multiple types of cancers and other diseases. In this review, we summarize the characteristics of Cables 1 and highlight the molecular mechanisms through which Cables1 regulates the development of cancer and other diseases. Finally, we discuss future challenges in demonstrating the role and potential application of Cables 1 in cancer and other diseases.

\section{Introduction}

Cdk5 and Abl enzyme substrate 1 (Cables1), also called ik3-1, was initially identified as a novel cyclin-dependent kinase (Cdks)-binding protein that connects Cdks (Cdk2, Cdk3, and Cdk5) with nonreceptor tyrosine kinases (Abl and Wee1) and that regulates the activity of Cdks by enhancing their Y15 phosphorylation. In neurons, Cables1 promotes Abl to phosphorylate Cdk5 at Y15, leading to an increase of Cdk5 kinase activity and the outgrowth of neurite (Zukerberg et al., 2000). In proliferating cells, Cables1 enhances Wee1 to phosphorylate Cdk5 at Y15, resulting in a decrease of Cdk2 kinase activity and inhibition of cell proliferation (Wu et al., 2001). The mRNA expression of Cables1 in adult mouse tissues is highest in brain. The transcript is also present in the lung, liver, and kidney, but is almost undetectable in the heart, spleen, smooth muscle, and testis (Zukerberg et al., 2000). It is now increasingly apparent that Cables 1 has crucial roles in the development of both tumors and neurons. The differential

This work was supported by the National Natural Science Foundation of China [Grants 31271444, 81201726, and, 8161101021], the Guangdong Natural Science Funds for Distinguished Young Scholar [Grant 2014A030306001], the Guangdong Special Support Program for Young Talent [Grant 2015TQ01R350], the Science and Technology Program of Guangdong [Grant 2016A050502027], and the Foundation for Research Cultivation and Innovation of Jinan University [Grant 21616119]. No potential conflicts of interest were disclosed.

J.-R.H. and G.-M.T. contributed equally to this work

https://doi.org/10.1124/mol.116.107730. interaction of Cables 1 with p53 family proteins, including p53, p63, and p73, makes Cables1 a multifaceted regulator of cell death (Tsuji et al., 2002; Wang et al., 2010). The observation of very frequent Cables1 loss in multiple types of cancers and of increased incidence of endometrial cancer in Cables $1^{-1-}$ mice strongly indicates that Cables 1 may have a suppressive effect on tumorigenesis (Dong et al., 2003; Tan et al., 2003; Zukerberg et al., 2004; Park do et al., 2007). Recently, our work revealed a novel tumor suppressor function of Cables1 in antagonizing proteasome subunit alpha type 3 (PSMA3) to increase the stability of cell cycle regulator p21 proteins (Shi et al., 2015a). In addition, we elucidated a dynamic regulatory system in which activated Akt can phosphorylate Cables 1 and recruit 14-3-3 to neutralize the tumor suppressor function of Cables1, suggesting that the Akt/Cables 1 interface may represent a novel anticancer target for potential therapeutic interventions (Shi et al., 2015b). As shown in the timeline of Cables1 research (Fig. 1), much work has been done to explore the biologic function of Cables 1 in physiologic and pathologic conditions over the past decade. Here, we provide a comprehensive summary of the role of Cables 1 in cancer and other diseases.

\section{The Characteristics of Cables 1}

The human Cables1 gene is located on 18q11.2-12.1 (Matsuoka et al., 2000; Zukerberg et al., 2000; Wu et al., 2001). The loss or deletion of the chromosome 18q, where previously characterized putative tumor suppressor genes

ABBREVIATIONS: Cables1, Cdk5 and Abl enzyme substrate 1; Cdks, cyclin-dependent kinase; PSMA3, proteasome subunit alpha type 3; 3D, three-dimensional. 


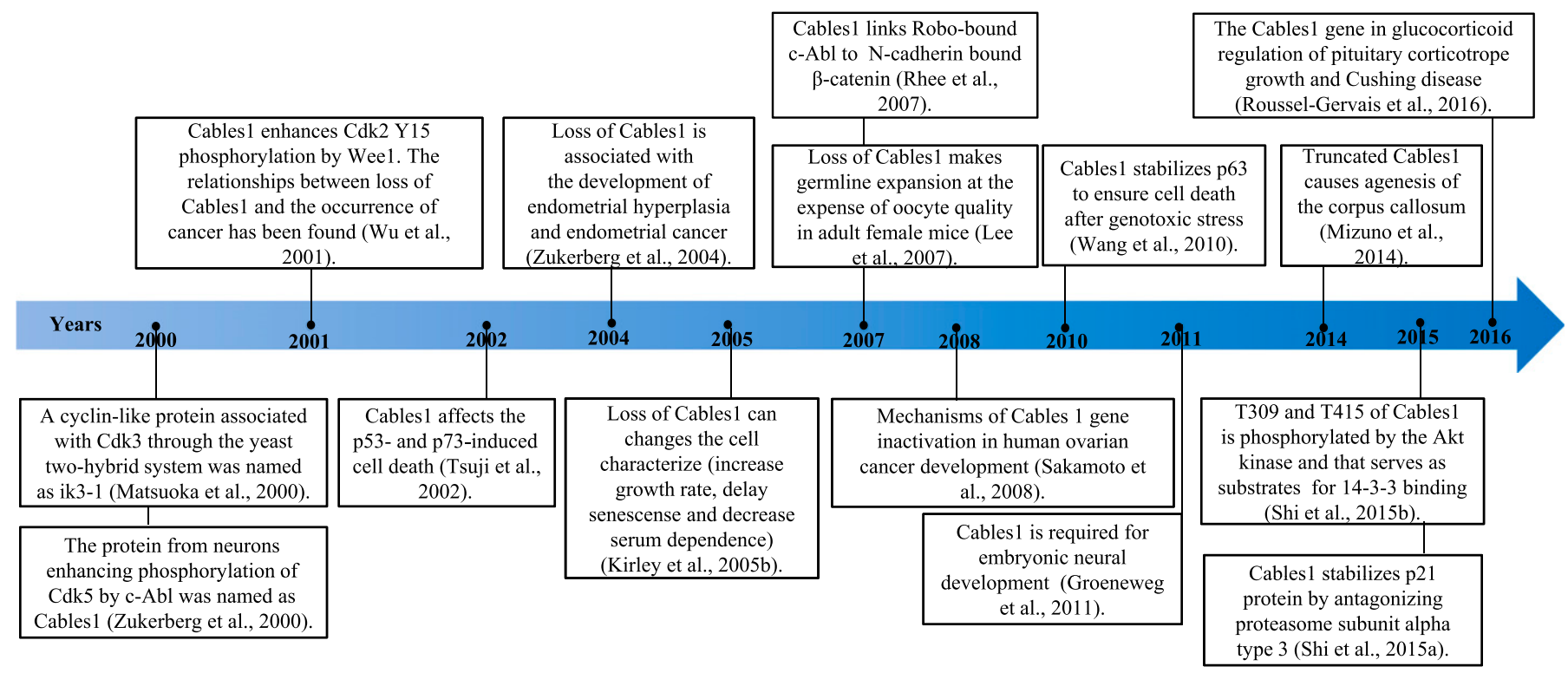

Fig. 1. The history of Cables1. The important events and years of Cables1 have been shown.

DCC (deleted in colorectal carcinoma), Smad2, and Smad4 are located, is one of the common chromosomal abnormalities in various types of cancers, including, for example, colorectal, ovarian, lung, and endometrial cancer (Tan et al., 2003; Bonifant and Waldman, 2005; Park et al., 2007; Morin, 2008). The human Cables1 gene encodes a 633-amino acid protein that predominantly localizing in the nucleus (Wu et al., 2001). There are three classic nuclear localization signals composed of three basic amino acids and either histidine or proline at amino acid positions 48,54 , and 406 of the Cables1 protein (Hicks and Raikhel, 1995; Wu et al., 2001; Christie et al., 2016). Cables1 protein also has six minimal SH3 domain binding motifs, two of which contain additional proline residues (PPXP and PXPP) in the $\mathrm{N}$ terminus of the protein with good potential for binding to the SH3 domain of the c-Abl and c-Src (Fig. 2A) (Cicchetti et al., 1992; Ren et al., 1993; Dai and Pendergast, 1995; Shi et al., 1995; Zukerberg et al., 2000). In addition, Cables1 contains two tyrosine-based sorting motifs (YXXLE), which are important in axonal growth cone sorting (Zukerberg et al., 2000). The $\mathrm{N}$-terminal 98 -amino acid region of Cables1 is necessary for the Cables1-tudor repeat associator with Pctaire 2 interaction (Yamochi et al., 2001a). The $\mathrm{C}$ terminus of Cables1 has a cyclinlike domain, which is a key element in the interaction of Cables1 with Cdks. The three-dimensional (3D) structure of the Cables1 cyclin-like domain has been previewed through the SWISS-MODEL according to 3D structures of Cyclin-A2 and Cyclin-T2 (Arnold et al., 2006; Benkert et al., 2011; Biasini et al., 2014), which have homologous sequence identities of $20.28 \%$ and $20.51 \%$, respectively (Fig. 2, B-E).

The regulation of Cables 1 at the transcriptional and post-transcriptional level has is largely unknown. Progesterone can induce Cables1 mRNA expression in low-grade endometrial cancer cells but not in high-grade endometrial cancer cells; a progesterone receptor antagonist is able to abrogate the progesterone-induced increase of Cables1 (DeBernardo et al., 2005). Additionally, knockdown of the Argonaut protein PiwiL2 reduces the expression of Cables 1 in adult mouse mesenchymal stem cells $(\mathrm{Wu}$ et al., 2010). Protein phosphorylation is a common posttranslational modification of proteins, causing a conformational change to modify the protein function (Cieśla et al., 2011). Cables1 can be phosphorylated by Cdk3 at S274 of mouse Cables1 (S313 of human Cables1) (Fig. 2A) (Yamochi et al., 2001b). Akt also phosphorylates Cables1 at T309 and T415 sites to recruit 14-3-3 binding (Shi et al., 2015b).

\section{The Role of Cables1 in Cancer}

The loss of Cables1 expression is detected with high frequency in human lung, colon, ovarian, and endometrial cancers, but not in breast and pancreatic cancers (Dong et al., 2003; Tan et al., 2003; Zukerberg et al., 2004; Park do et al., 2007) (Table 1). In colorectal and ovarian cancers, promoter methylation and loss of heterozygosity are two main reasons for Cables gene inactivation, and the overexpression of Cables1 significantly inhibits the growth of these cancer cells. (Park et al., 2007; Sakamoto et al., 2008). In addition, there is aberrant splicing of Cables1 genes in endometrial and colon cancers (Zhang et al., 2005). Knockout of Cables1 in mice leads to an increased incidence of endometrial cancer, a reduced survival rate after unopposed estrogen treatment, and an increased incidence of colorectal cancer in response to 1,2dimethylhydrazine (Zukerberg et al., 2004; Kirley et al., 2005a). Mouse embryonic fibroblasts isolated from $\mathrm{Cables}^{-1-}$ mice show an increased rate of growth, delayed onset of senescence, and decreased serum dependence (Kirley et al., $2005 \mathrm{~b})$. In the $A p c^{\mathrm{Min} /+}$ mouse model, the loss of Cables1 promotes tumor progression and activates the Wnt/ $\beta$-catenin signaling pathway (Arnason et al., 2013). Together, these pieces of evidence strongly indicate that Cables 1 functions as a tumor suppressor.

Mechanistically, Cables1 can promote the phosphorylation of Wee1 and its binding to Cdk2 (Wu et al., 2001). Cdk2 is a small serine/threonine kinase that regulates cell cycle 


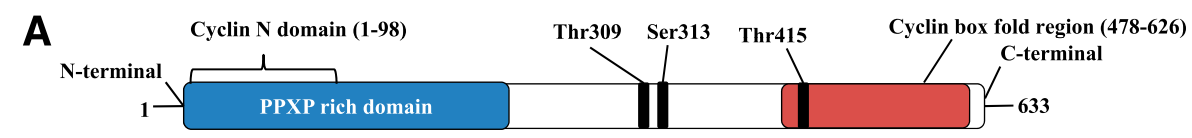

B
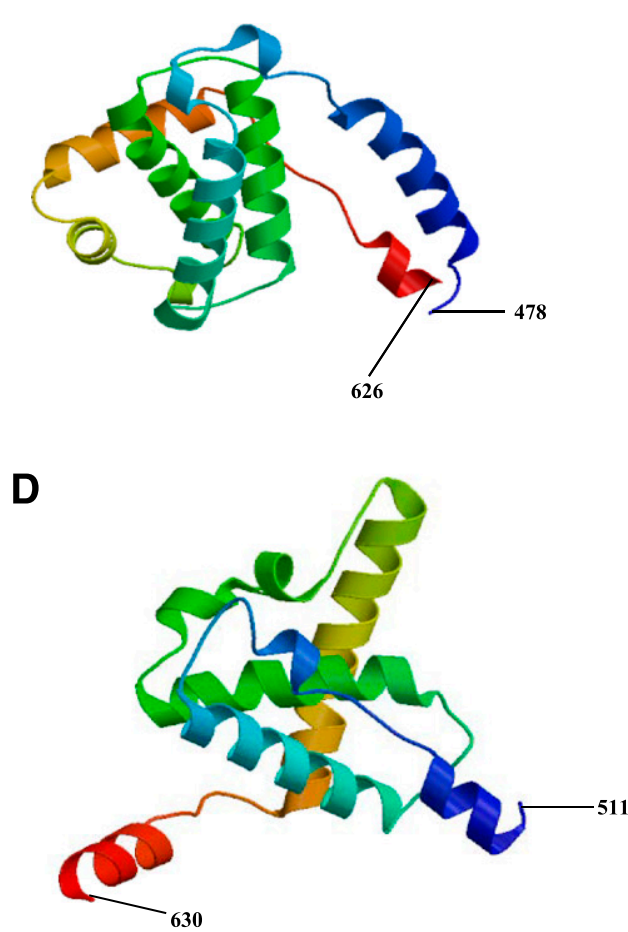

C

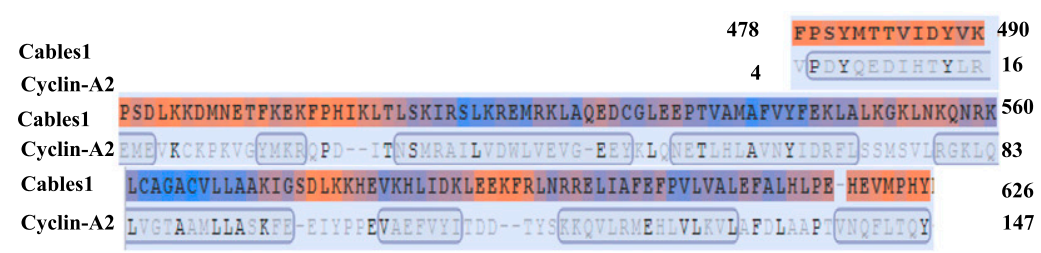

E

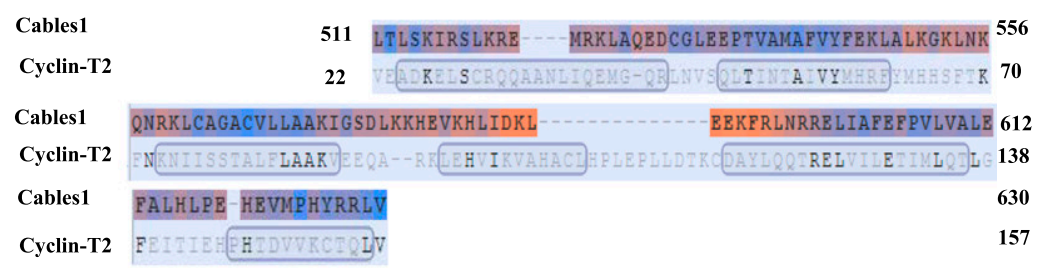

Fig. 2. The prediction of the 3D structure of Cables1 cyclin-like domain with SWISS-MODEL. (A) A schematic representation of human Cables1. (B) The prediction of the 3D model of Cables1 cyclin-like domain is done according to Cyclin-A2. (C) The alignment of amino acid sequences between cyclin-like domains of Cables1 and Cyclin-A2. (D) The prediction of the 3D model of Cables1 cyclin-like domain is done according to Cyclin-T2. (E) The alignment of amino acid sequences between cyclin-like domains of Cables1 and Cyclin-T2.

progression; its activity is tightly controlled by phosphorylation (Elledge et al., 1992; Hirai et al., 1992; Pagano et al., 1993). Wee1 phosphorylates Cdk2 at Y15, leading to the inhibition of Cdk2 activity (Parsons, 1998; Wroble et al., 2007). Therefore, Cables1 can inhibit cell proliferation via enhancing Cdk2 Y15 phosphorylation by Wee1 (Wu et al.,
2001), which contributes to its tumor suppressor function. Cables1 also binds to p53 family proteins, including p53, p63, and p73, which play a critical role in tumorigenesis (Irwin and Kaelin, 2001; Botchkarev and Flores, 2014; Orzol et al., 2015). In U2OS osteosarcoma cells, ectopically expressed Cables1 potentiates p53-induced cell death but not p73-induced cell

TABLE 1

Summary of the published Cables1 expression in human tumors

\begin{tabular}{llcl}
\hline \multicolumn{1}{c}{ Tumors $(n)$} & \multicolumn{1}{c}{ Substyles $(n)$} & Loss (\%) & \multicolumn{1}{c}{ Reference } \\
\hline Non-small cell lung cancer (113) & & 45 & (Tan et al., 2003) \\
Squamous cell carcinoma (20) & & 60 & \\
Breast cancer (20) & & 0 & \\
Pancreas cancer (20) & & 0 & (Wu et al., 2001) \\
Colon cancer (20) & & 55 & (Park et al., 2007) \\
Colorectal cancer (160) & & 65 & (Zukerberg et al., 2004) \\
Endometrial cancers (20) & Hyperplasia (22) & 95 & \\
& Endometrioid (54) & 77.2 & \\
Endometrial cancer (103) & Serous (14) & 94.4 & (DeBernardo et al., 2005) \\
& Clear cell (13) & 85.7 & \\
Ovarian cancer (24) & Serous carcinomas (14) & 84.6 & \\
& Endometrioid carcinomas (10) & 79 & (Dong et al., 2003) \\
& Serous (26) & 50 & \\
& Endometrioid (17) & 96.5 & \\
Ovarian cancer (70) & Clear cell (17) & 94.2 & \\
& Mucinous (6) & 53 & \\
& Transitional (4) & 100 & (Sakamoto et al., 2008) \\
\hline
\end{tabular}




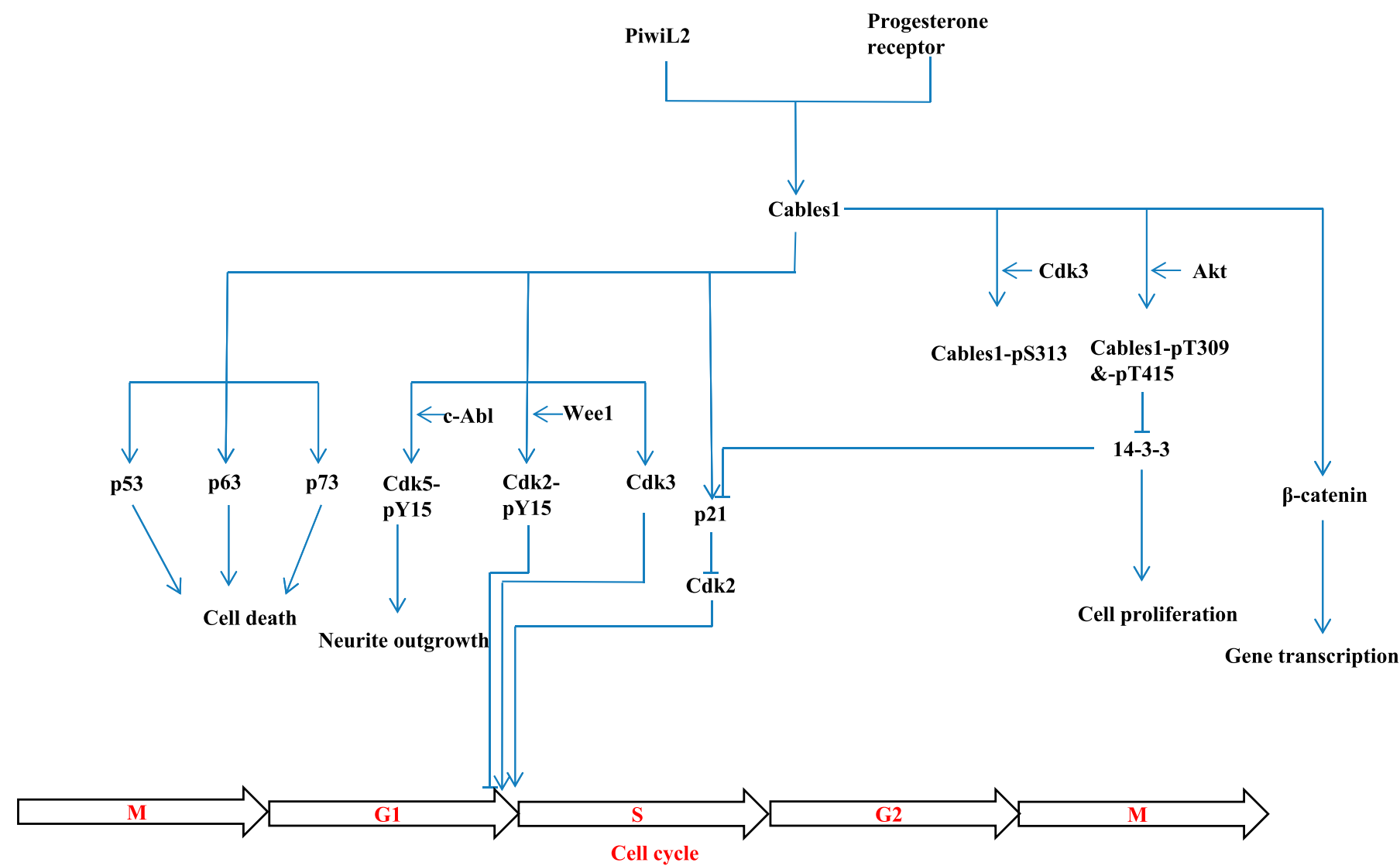

Fig. 3. The signaling pathways of Cables1. PiwiL2 and progesterone can induce Cables1 expression. Cables1 enhances the Y15 phosphorylation of Cdk2 or Cdk5 by Wee1 or c-Abl respectively, resulting in the inhibition of cell proliferation or the outgrowth of neurites. Cell death mediated by p53 family proteins and gene transcription mediated by $\beta$-catenin can be strengthened by the direct interactions with Cables 1 . Additionally, Cables 1 can be phosphorylated by Cdk3 at S311, and by Akt at T309 and T415 sites, which recruits 14-3-3 binding to promote cell proliferation.

death, and coexpression of a Cables1 deletion mutant lacking cyclin-like domain inhibits p73-induced cell death but not p53-induced cell death (Tsuji et al., 2002). Cables1 interacts with $\mathrm{p} 63$ to protect it from proteasomal degradation, promoting cell death after genotoxic stress (Wang et al., 2010). Recently, we identified a novel function of Cables1 as a tumor suppressor by controlling the protein stability of Cdk inhibitor 1A (also known as p21/Cip1) (Shi et al., 2015a). Our data show that Cables1 competes with PSMA3 to bind p21, and protects p21 from PSMA3mediated proteasomal degradation; the expression level of Cables1 is correlated with that of p21 in human lung cancer tissues (Shi et al., 2015a). Additionally, we found a phosphorylation-dependent and 14-3-3-mediated mechanism that regulates the tumor suppressor function of Cables1 (Shi et al., 2015b). Akt directly interacts with and phosphorylates Cables1 to recruit 14-3-3 to the complex; activated Akt is able to prevent cell apoptosis induced by Cables1 (Shi et al., 2015b).

\section{The Role of Cables1 in the Other Diseases}

In the nervous system, Cdk5 and c-Abl play pivotal roles during the development of neurons (Lee et al., 2008; Cancino et al., 2011). Cables1, initially identified as an adaptor protein of $\mathrm{Cdk} 5$ and c-Abl, enhances the c-Abl-mediated phosphorylation of Y15 of Cdk5, which increases the kinase activity of
Cdk5 and promotes neurite outgrowth (Zukerberg et al., 2000). After binding of the secreted axon guidance cue Slit to its Robo receptor, Cables 1 is recruited to Robo-associated Abl to form a multimolecular complex by directly binding to N-cadherin-associated $\beta$-catenin. This leads to Abl-mediated phosphorylation of $\beta$-catenin on Y489 and decreases the affinity of $\beta$-catenin with $\mathrm{N}$-cadherin, resulting in the loss of $\mathrm{N}$-cadherin function and activation of transcription mediated by $\beta$-catenin and the transcription factor Tcf/Lef (Rhee et al., 2007). In a transgenic mouse model of agenesis of the corpus callosum, the genomic region containing exon 4 of Cables1 is deleted by transgene insertion, and the truncated Cables 1 containing only exons $1-3$ indeed impairs callosal formation through a dominant-negative effect (Mizuno et al., 2014). Additionally, it has been reported that Cables 1 is required for embryonic neural development of zebrafish in a mechanism likely involving interactions with $\mathrm{Cdk} 5$ (Groeneweg et al., 2011).

Recently, loss of Cables1 expression was found in approximately $55 \%$ of corticotropic adenomas, which finally results in Cushing disease and glucocorticoid resistance. Cables1 expression can be induced by glucocorticoids in the mouse corticotropic tumor cells AtT-20 (Roussel-Gervais et al., 2016). Knockout of Cables1 gene in mice has minimal to no effect on hematopoietic stem cell dynamics, but female Cables1 $1^{-1-}$ mice show a significant expansion of germline at the expense of oocyte quality throughout adulthood (Lee et al., 2007). 


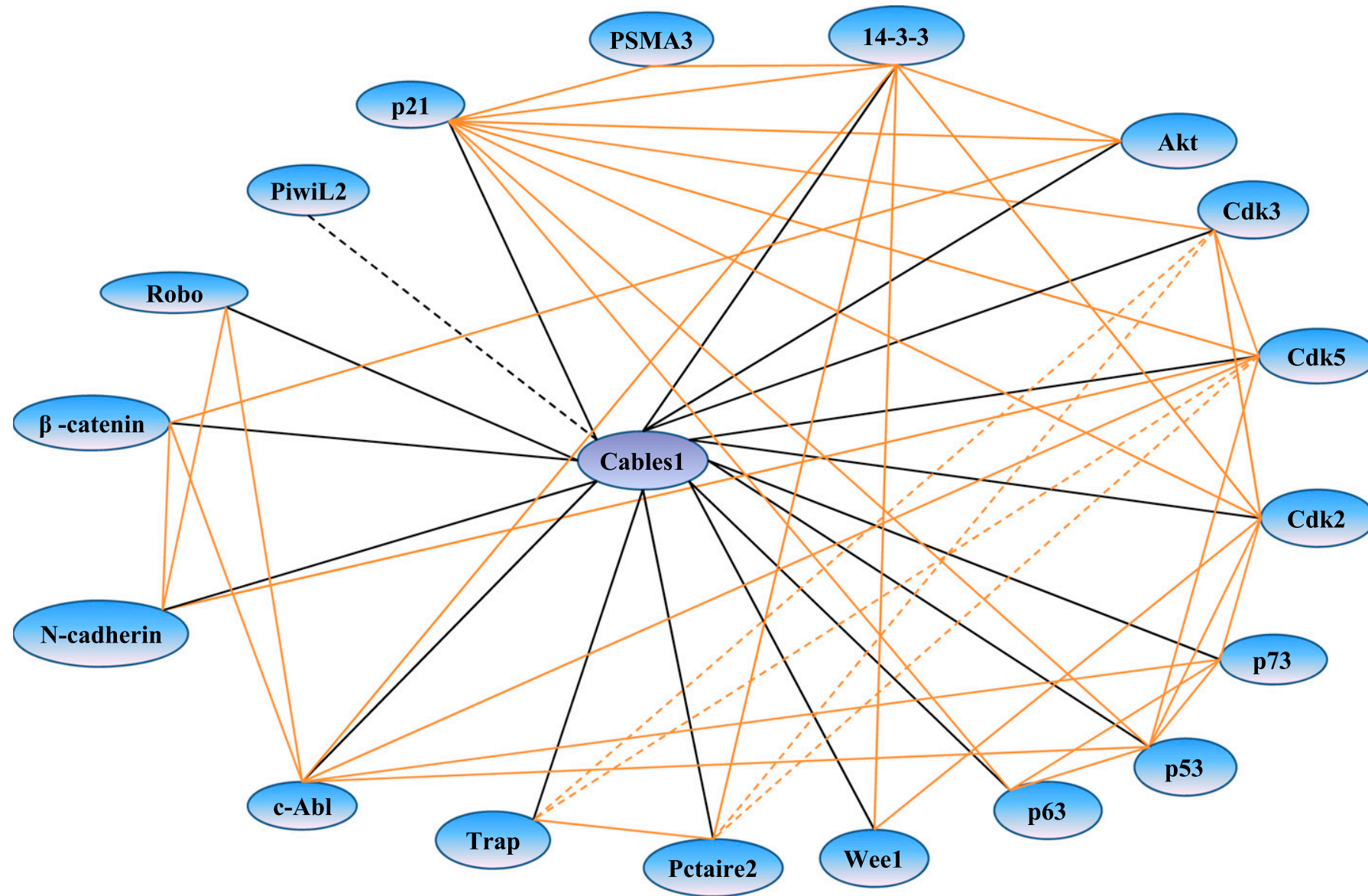

Fig. 4. The interaction network of Cables1. The black line respects the interactions of Cables 1 and the other proteins. The orange line respects the interactions among the proteins that can interact with Cables1. The dotted line represents the interactions that have not been confirmed.

Interestingly, Cables1 expression is significantly decreased in both pediatric and adult samples of male genital lichen sclerosus (Edmonds et al., 2011).

\section{Future Prospects}

The growing understanding of the functional roles of Cables1 has already led to the delineation of signaling pathways involving Cables1 (Fig. 3). The interaction network of Cables 1 with, for example, Cdks, p53 family proteins, 14-3-3, and $\beta$-catenin, indicates that Cables 1 is a signaling hub for the regulation of the cell cycle, cell growth, and cell death (Fig. 4). However, there is much left to address. How is Cables 1 expression regulated at the transcriptional level? The transcriptional factors mediating Cables 1 expression are still unknown. Do any microRNAs or long noncoding RNAs affect Cables1 expressions? Besides phosphorylation, is Cables1 protein subject to other post-translational modifications, such as acetylation, methylation, and ubiquitination? Is the function of Cables 1 affected by these modifications? Due to the loss of Cables 1 expression in certain types of cancers, it is likely that Cables1 has value as a diagnostic or prognostic biomarker in some cancers. The development of small molecules or technologies that can specifically induce Cables 1 expression to suppress cancer cell proliferation may provide a new strategy for cancer treatment. These challenging questions supply exciting avenues for researching the role and potential application of Cables 1 in cancer and other diseases in the future.

\section{Authorship contributions}

Wrote or contributed to the writing of the manuscript: Huang, Tan, $\mathrm{Li}$ and $\mathrm{Sh}$

\section{References}

Arnason T, Pino MS, Yilmaz O, Kirley SD, Rueda BR, Chung DC, and Zukerberg LR (2013) Cables1 is a tumor suppressor gene that regulates intestinal tumor progression in Apc(Min) mice. Cancer Biol Ther 14:672-678.

Arnold K, Bordoli L, Kopp J, and Schwede T (2006) The SWISS-MODEL workspace: a web-based environment for protein structure homology modelling. Bioinformatics 22:195-201.

Benkert P, Biasini M, and Schwede T (2011) Toward the estimation of the absolute quality of individual protein structure models. Bioinformatics 27:343-350.

Biasini M, Bienert S, Waterhouse A, Arnold K, Studer G, Schmidt T, Kiefer F, Gallo Cassarino T, Bertoni M, Bordoli L, and Schwede T (2014) SWISS-MODEL: modelling protein tertiary and quaternary structure using evolutionary information. Nucleic Acids Res 42:W252-W258.

Bonifant CL and Waldman T (2005) 'Cables' suspends cancer in mice. Cancer Biol Ther 4:864-865.

Botchkarev VA and Flores ER (2014) p53/p63/p73 in the epidermis in health and disease. Cold Spring Harb Perspect Med 4:a015248.

Cancino GI, Perez de Arce K, Castro PU, Toledo EM, von Bernhardi R, and Alvarez AR (2011) c-Abl tyrosine kinase modulates tau pathology and Cdk5 phosphorylation in AD transgenic mice. Neurobiol Aging 32:1249-1261.

Christie M, Chang CW, Róna G, Smith KM, Stewart AG, Takeda AA, Fontes MR, Stewart M, Vértessy BG, Forwood JK, et al. (2016) Structural Biology and Regulation of Protein Import into the Nucleus. J Mol Biol 428:2060-2090.

Cicchetti P, Mayer BJ, Thiel G, and Baltimore D (1992) Identification of a protein that binds to the SH3 region of Abl and is similar to Bcr and GAP-rho. Science 257:803-806.

Cieśla J, Frączyk T, and Rode W (2011) Phosphorylation of basic amino acid residues in proteins: important but easily missed. Acta Biochim Pol 58:137-148.

Dai $\mathrm{Z}$ and Pendergast AM (1995) Abi-2, a novel SH3-containing protein interacts with the c-Abl tyrosine kinase and modulates c-Abl transforming activity. Genes Dev $\mathbf{9}$ : 2569-2582. 
DeBernardo RL, Littell RD, Luo H, Duska LR, Oliva E, Kirley SD, Lynch MP, Zukerberg LR, and Rueda BR (2005) Defining the extent of cables loss in endometrial cancer subtypes and its effectiveness as an inhibitor of cell proliferation in malignant endometrial cells in vitro and in vivo. Cancer Biol Ther 4:103-107.

Dong Q, Kirley S, Rueda B, Zhao C, Zukerberg L, and Oliva E (2003) Loss of cables, a novel gene on chromosome 18q, in ovarian cancer. Mod Pathol 16:863-868.

Edmonds E, Barton G, Buisson S, Francis N, Gotch F, Game L, Haddad M, Dinneen $\mathrm{M}$, and Bunker C (2011) Gene expression profiling in male genital lichen sclerosus. Int $J$ Exp Pathol 92:320-325.

Elledge SJ, Richman R, Hall FL, Williams RT, Lodgson N, and Harper JW (1992) CDK2 encodes a 33-kDa cyclin A-associated protein kinase and is expressed before CDC2 in the cell cycle. Proc Natl Acad Sci U S A 89:2907-2911.

Groeneweg JW, White YA, Kokel D, Peterson RT, Zukerberg LR, Berin I, Rueda BR, and Wood AW (2011) cables1 is required for embryonic neural development: molecular, cellular, and behavioral evidence from the zebrafish. Mol Reprod Dev 78:22-32.

Hicks GR and Raikhel NV (1995) Protein import into the nucleus: an integrated view. Annu Rev Cell Dev Biol 11:155-188.

Hirai T, Yamashita M, Yoshikuni M, Tokumoto T, Kajiura H, Sakai N, and Nagahama Y (1992) Isolation and characterization of goldfish cdk2, a cognate variant of the cell cycle regulator cdc2. Dev Biol 152:113-120.

Irwin MS and Kaelin WG (2001) p53 family update: p73 and p63 develop their own identities. Cell Growth Differ 12:337-349.

Kirley SD, D’Apuzzo M, Lauwers GY, Graeme-Cook F, Chung DC, and Zukerberg LR (2005a) The Cables gene on chromosome 18Q regulates colon cancer progression in vivo. Cancer Biol Ther 4:861-863.

Kirley SD, Rueda BR, Chung DC, and Zukerberg LR (2005b) Increased growth rate, delayed senescense and decreased serum dependence characterize cables-deficient cells. Cancer Biol Ther 4:654-658.

Lee HJ, Sakamoto H, Luo H, Skaznik-Wikiel ME, Friel AM, Niikura T, Tilly JC, Niikura Y, Klein R, Styer AK, et al. (2007) Loss of CABLES1, a cyclin-dependent kinase-interacting protein that inhibits cell cycle progression, results in germline expansion at the expense of oocyte quality in adult female mice. Cell Cycle $\mathbf{6}$ $2678-2684$.

Lee JH, Jeong MW, Kim W, Choi YH, and Kim KT (2008) Cooperative roles of c-Abl and Cdk5 in regulation of p53 in response to oxidative stress. J Biol Chem 283 : 19826-19835.

Matsuoka M, Matsuura Y, Semba K, and Nishimoto I (2000) Molecular cloning of a cyclin-like protein associated with cyclin-dependent kinase 3 (cdk 3 ) in vivo. Biochem Biophys Res Commun 273:442-447.

Mizuno S, Tra DT, Mizobuchi A, Iseki H, Mizuno-Iijima S, Kim JD, Ishida J, Matsuda Y, Kunita S, Fukamizu A, et al. (2014) Truncated Cables1 causes agenesis of the corpus callosum in mice. Lab Invest 94:321-330.

Morin PJ (2008) Learning about ovarian tumorigenesis by watching Cables. Cancer Biol Ther 7:189-190.

Orzol P, Holcakova J, Nekulova M, Nenutil R, Vojtesek B, and Coates PJ (2015) The diverse oncogenic and tumour suppressor roles of p63 and p73 in cancer: a review by cancer site. Histol Histopathol 30:503-521.

Pagano M, Pepperkok R, Lukas J, Baldin V, Ansorge W, Bartek J, and Draetta G (1993) Regulation of the cell cycle by the cdk2 protein kinase in cultured human fibroblasts. J Cell Biol 121:101-111.

Park DY, Sakamoto H, Kirley SD, Ogino S, Kawasaki T, Kwon E, Mino-Kenudson M Lauwers GY, Chung DC, Rueda BR, et al. (2007) The Cables gene on chromosome $18 q$ is silenced by promoter hypermethylation and allelic loss in human colorectal cancer. Am J Pathol 171:1509-1519.

Parsons R (1998) Phosphatases and tumorigenesis. Curr Opin Oncol 10:88-91.

Ren R, Mayer BJ, Cicchetti P, and Baltimore D (1993) Identification of a ten-amino acid proline-rich SH3 binding site. Science 259:1157-1161.
Rhee J, Buchan T, Zukerberg L, Lilien J, and Balsamo J (2007) Cables links Robobound Abl kinase to N-cadherin-bound beta-catenin to mediate Slit-induced modulation of adhesion and transcription. Nat Cell Biol 9:883-892.

Roussel-Gervais A, Couture C, Langlais D, Takayasu S, Balsalobre A, Rueda BR, Zukerberg LR, Figarella-Branger D, Brue T, and Drouin J (2016) The Cables1 Gene in Glucocorticoid Regulation of Pituitary Corticotrope Growth and Cushing Disease. $J$ Clin Endocrinol Metab 101:513-522.

Sakamoto H, Friel AM, Wood AW, Guo L, Ilic A, Seiden MV, Chung DC, Lynch MP, Serikawa T, Munro E, et al. (2008) Mechanisms of Cables 1 gene inactivation in human ovarian cancer development. Cancer Biol Ther 7:180-188.

Shi Y, Alin K, and Goff SP (1995) Abl-interactor-1, a novel SH3 protein binding to the carboxy-terminal portion of the Abl protein, suppresses v-abl transforming activity. Genes Dev 9:2583-2597.

Shi Z, Li Z, Li ZJ, Cheng K, Du Y, Fu H, and Khuri FR (2015a) Cables1 controls p21/Cip1 protein stability by antagonizing proteasome subunit alpha type 3 . Oncogene 34:2538-2545.

Shi Z, Park HR, Du Y, Li Z, Cheng K, Sun SY, Li Z, Fu H, and Khuri FR (2015b) Cables1 complex couples survival signaling to the cell death machinery. Cancer Res 75:147-158.

Tan D, Kirley S, Li Q, Ramnath N, Slocum HK, Brooks JS, Wu CL, and Zukerberg LR (2003) Loss of cables protein expression in human non-small cell lung cancer: a tissue microarray study. Hum Pathol 34:143-149.

Tsuji K, Mizumoto K, Yamochi T, Nishimoto I, and Matsuoka M (2002) Differential effect of ik3-1/cables on p53- and p73-induced cell death. $J$ Biol Chem 277: 2951-2957.

Wang N, Guo L, Rueda BR, and Tilly JL (2010) Cables1 protects p63 from proteasomal degradation to ensure deletion of cells after genotoxic stress. EMBO Rep 11: 633-639.

Wroble BN, Finkielstein CV, and Sible JC (2007) Wee1 kinase alters cyclin E/Cdk2 and promotes apoptosis during the early embryonic development of Xenopus laevis. BMC Dev Biol 7:119.

Wu CL, Kirley SD, Xiao H, Chuang Y, Chung DC, and Zukerberg LR (2001) Cables enhances cdk2 tyrosine 15 phosphorylation by Wee1, inhibits cell growth, and is lost in many human colon and squamous cancers. Cancer Res 61:7325-7332.

Wu Q, Ma Q, Shehadeh LA, Wilson A, Xia L, Yu H, and Webster KA (2010) Expression of the Argonaute protein PiwiL2 and piRNAs in adult mouse mesenchymal stem cells. Biochem Biophys Res Commun 396:915-920.

Yamochi T, Nishimoto I, Okuda T, and Matsuoka M (2001a) ik3-1/Cables is associated with Trap and Pctaire2. Biochem Biophys Res Commun 286:1045-1050.

Yamochi T, Semba K, Tsuji K, Mizumoto K, Sato H, Matsuura Y, Nishimoto I, and Matsuoka M (2001b) ik3-1/Cables is a substrate for cyclin-dependent kinase 3 (cdk 3). Eur J Biochem 268:6076-6082.

Zhang H, Duan HO, Kirley SD, Zukerberg LR, and Wu CL (2005) Aberrant splicing of cables gene, a CDK regulator, in human cancers. Cancer Biol Ther 4:1211-1215.

Zukerberg LR, Patrick GN, Nikolic M, Humbert S, Wu CL, Lanier LM, Gertler FB, Vidal M, Van Etten RA, and Tsai LH (2000) Cables links Cdk5 and c-Abl and facilitates Cdk5 tyrosine phosphorylation, kinase upregulation, and neurite outgrowth. Neuron 26:633-646.

Zukerberg LR, DeBernardo RL, Kirley SD, D’Apuzzo M, Lynch MP, Littell RD, Duska LR, Boring L, and Rueda BR (2004) Loss of cables, a cyclin-dependent kinase regulatory protein, is associated with the development of endometrial hyperplasia and endometrial cancer. Cancer Res 64:202-208.

Address correspondence to: Zhi Shi, 601 Huangpu Road West, Guangzhou 510632, People's Republic of China. E-mail: tshizhi@jnu.edu.cn 